\title{
Article \\ Effects of the Ethyne Flow Ratio on Structures and Mechanical Properties of Reactive High Power Impulse Magnetron Sputtering Deposited Chromium-Carbon Films
}

\author{
Chin-Chiuan Kuo * and Shu-Ping Chang \\ Department of Mechanical and Computer Aided Engineering, National Formosa University, \\ Huwei, Yunlin County 63201, Taiwan; 40871103@gm.nfu.edu.tw \\ * Correspondence: cckuo@nfu.edu.tw; Tel.: +886-5631-3492
}

Citation: Kuo, C.-C.; Chang, S.-P. Effects of the Ethyne Flow Ratio on Structures and Mechanical Properties of Reactive High Power Impulse Magnetron Sputtering Deposited Chromium-Carbon Films. Coatings 2021, 11, 873. https://doi.org/ 10.3390/coatings11080873

Received: 30 June 2021

Accepted: 20 July 2021

Published: 22 July 2021

Publisher's Note: MDPI stays neutral with regard to jurisdictional claims in published maps and institutional affiliations.

Copyright: (c) 2021 by the authors. Licensee MDPI, Basel, Switzerland. This article is an open access article distributed under the terms and conditions of the Creative Commons Attribution (CC BY) license (https:// creativecommons.org/licenses/by/ $4.0 /)$.

\begin{abstract}
Chromium-carbon films were deposited by utilizing reactive high-power impulse magnetron sputtering with different mixture ratios of ethyne and argon with a constant deposition total pressure while the deposition temperature, pulse frequency, duty cycle and average power of the chromium cathode remain the same. The microstructure and chemical bonding of the obtained films within different composition were compared. The results show that with the increasing ethyne ratio, the carbon content in films increases linearly with two slopes. Moreover, the microstructure of the deposited film changes from a dense glassy structure into a columnar structure, even a clusters structure. The sp2-C bonding in films decreases but the $\mathrm{Cr}-\mathrm{C}$ bonding increases with decreasing the ethyne ratio. This reveals the main phase of films changes from a hydrogenated amorphous carbon phase into a glassy amorphous chromium carbide phase. Such changes of the microstructure and phase cause a large difference on the film hardness and elasticity.
\end{abstract}

Keywords: chromium carbide; amorphous carbon; ethyne; high-power impulse magnetron sputtering

\section{Introduction}

By using plasma-enhanced physical vapor deposition techniques, various transition metal-contained carbon, metal carbides, carbon-contained alloys or multiphase composite metal-carbon films can be synthesized by tuning deposition parameters. Each phase exhibits individual electrical, mechanical, chemical properties and subsequent conductivity, tribology, corrosion resistance performance [1-21]. Amorphous carbon phases with high hardness/elastic modulus ratio and low surface energy provides a low friction wear resistance [12]. Carbide phases with the chemical bonding, which is a mixture of metallic, covalent, ionic characters, usually provide the high hardness, high moduli, chemical stability and low electrical resistivity [22]. Therefore, transition metal-carbon (TM-C) films have been widely used as the wear or the corrosion resistant protective coatings $[6,9,20,23]$. Some metal elements, such as chromium and aluminum, in these TM-C systems, form an extreme thin oxide layer to block the further oxidation and the other corrosive substances. Their potential in long service electrical contact applications has been demonstrated [13].

The $\mathrm{Cr}-\mathrm{C}$ system has several interesting characteristics. For example, the hardness of the synthesized chromium carbide is varied up to ten times depending on the deposition processes and the composition [13-15]. The most unique property of the $\mathrm{Cr}-\mathrm{C}$ system is the wide range glass forming ability [24-28]. This feature benefits tailoring the film structure and subsequent film functions by adjusting deposition conditions $[10,29,30]$.

In our previous work, the experiment on depositing chromium-carbon films by utilizing reactive high-power impulse magnetron sputtering (HiPIMS) was carried out [31]. HiPIMS provides high degree ionization of the sputtered species. This enables the alteration of the kinetic energy of the incident ions and the mobility of the adatoms by controlling substrate biasing and the pulse power density [32-35]. Films with higher density and 
better functions can be therefore achieved with the cost of lower deposition rate. $\mathrm{Cr}-\mathrm{C}$ films deposited at different synchronized substrate bias voltage and argon/ethyne gas flow ratio from 1:1 to 12:1 were compared in the previous work [31]. It was found that the main structure of all the obtained films in the previous work is hydrogenated amorphous carbon. Although applying synchronized substrate bias successfully prevented the substrate voltage drop and inhibited arc discharge on deposited film [31,36,37]. A part of films presents loosen structures which seemed contrary to above-mentioned features of denser films via HiPIMS. Enhancing the synchronized negative substrate bias voltage did improve the density and hardness of HiPIMS-deposited $\mathrm{Cr}-\mathrm{C}$ films. However, all the obtained films hardness values were still relatively low while being compared with the results of the other studies $[7,9,12,13,18,20]$. Neither features of the glass forming nor transition from metal mode to compound mode depositions, which are commonly seen in direct current magnetron sputtering (dcMS) $\mathrm{Cr}-\mathrm{C}$ system $[12,25,28]$, were found. Therefore, the range of argon/ethyne gas flow ratio should be extended in order to fully discover the relationship between the film structure and the argon/ethyne gas flow ratio during the reactive HiPIMS deposition of $\mathrm{Cr}-\mathrm{C}$ coatings. In this study, the films from $\mathrm{Cr}$-rich to $\mathrm{C}$-rich contents were deposited by using reactive HiPIMS technique. The microstructure and mechanical properties of the different films were compared to fully discover the relationship.

\section{Materials and Methods}

Cr-C films were deposited onto $\mathrm{Si}$ (100) wafer chips substrate in a HiPIMS deposition system. The substrates were placed facing the chromium target at a distance of $100 \mathrm{~mm}$. One unipolar HiPIMS power supply (Hüttinger TruPlasma Unipolar 4001, TRUMPF, Ditzingen, Germany) were connected to the rectangle chromium cathode $(432 \mathrm{~mm} \times 76 \mathrm{~mm} \times 13 \mathrm{~mm})$ with an unbalanced magnetron. One unipolar substrate bias power supply (Hüttinger TruPlasma Bias 4010 G2, TRUMPF, Ditzingen, Germany) was connected to the substrate holder.

After vacuuming to the base pressure of $6 \times 10^{-3} \mathrm{~Pa}$, the argon was introduced into the chamber and the glow discharge plasma substrate cleaning was proceeded at $2.7 \mathrm{~Pa}$ by applying direct current $-1000 \mathrm{~V}$ substrate bias voltage for $40 \mathrm{~min}$. After argon glow discharge plasma cleaning, the pressure was further reduced to $0.8 \mathrm{~Pa}$. The HiPIMS plasma was initiated on the $\mathrm{Cr}$ target and the $-1000 \mathrm{~V}$ substrate bias voltage was switched to the unipolar pulsed mode and synchronized with the target HiPIMS pulses to proceed the $\mathrm{Cr}$ ion bombardment for $40 \mathrm{~s}$. The reasons to apply the synchronized substrate bias can be seen in the other research $[32,38]$ and our previous works $[31,36,37]$. Due to the recycling of ions and the flight delay of ions $[33,38,39]$, the pulse width of the substrate bias voltage was set to 1.75-fold of HiPIMS pulses to optimally accelerate the $\mathrm{Cr}$ ion flux. The argon plasma cleaning and $\mathrm{Cr}$ ion bombardment generate heat in the substrate and raises the temperature to near $200^{\circ} \mathrm{C}$.

A series of different $\mathrm{Cr}-\mathrm{C}$ films were deposited at a same total pressure of $0.8 \mathrm{~Pa}$ with various $\mathrm{Ar} / \mathrm{C}_{2} \mathrm{H}_{2}$ gas flow ratio value, 10:1, 12:1, 14:1, 16:1, 24:1 and 38:1, respectively. The HiPIMS pulse voltage and current varied with the $\mathrm{C}_{2} \mathrm{H}_{2}$ gas flow ratio while keeping a constant average HiPIMS power of $3 \mathrm{~kW}$. The synchronized substrate bias voltages were set to the same $-150 \mathrm{~V}$. The deposition time was $90 \mathrm{~min}$. The deposition parameters are listed in Table 1.

The chemical bonding and compositions of the films were analyzed by using the electron spectroscopy for chemical analysis (ESCA, ULVAC-PHI, PHI 5000 VersaProbe, ULVAC-PHI, Chigasaki, Japan), also known as X-ray photoelectron spectroscopy (XPS), after the removal of surface contamination by conducting the $180 \mathrm{~s}$ argon ion bombardment. An X-ray diffractometer (XRD, D8 Discover X-ray diffractometer, Bruker, Billerica, MA, USA) with a $\mathrm{Cu} K \alpha$ radiation source was used to characterize the crystallinity of the films. A Raman spectrometer (PROTRUSTECH, Tainan, Taiwan) was used to determine the presence of carbon phases in the $\mathrm{Cr}-\mathrm{C}$ films. The surface and cross-sectional morphologies of deposited $\mathrm{Cr}-\mathrm{C}$ films were observed by using a scanning electron microscope (SEM, S-4800 Cold Field Emission Scanning Electron Microscope, Hitachi, Tokyo, Japan). The film 
thickness was estimated from the SEM cross-sectional images. The thickness of obtained $\mathrm{Cr}-\mathrm{C}$ films is between 2.1 to $2.9 \mu \mathrm{m}$. The hardness and the modulus of elasticity of $\mathrm{Cr}-$ C films were evaluated by applying the nanoindentation (TTX-NH3, Anton Paar, Graz, Austria). Settings of the analysis instruments were as the same as described in the previous works [31,36,37].

Table 1. Parameters for the deposition of chromium-carbon films.

\begin{tabular}{|c|c|c|}
\hline \multicolumn{2}{|c|}{ Deposition Parameters } & Value \\
\hline \multirow{3}{*}{ Atmosphere } & Pressure $(\mathrm{Pa})$ & 0.8 \\
\hline & & $10: 1\left(9.1 \% \mathrm{C}_{2} \mathrm{H}_{2}\right), 12: 1\left(7.7 \% \mathrm{C}_{2} \mathrm{H}_{2}\right)$, \\
\hline & $\mathrm{Ar} / \mathrm{C}_{2} \mathrm{H}_{2}$ gas flow ratio & $\begin{array}{c}14: 1\left(6.7 \% \mathrm{C}_{2} \mathrm{H}_{2}\right), 16: 1\left(5.9 \% \mathrm{C}_{2} \mathrm{H}_{2}\right), \\
24: 1\left(4 \% \mathrm{C}_{2} \mathrm{H}_{2}\right), 38: 1\left(2.6 \% \mathrm{C}_{2} \mathrm{H}_{2}\right)\end{array}$ \\
\hline \multirow{5}{*}{ Target HiPIMS power } & Average power (kW) & 3 \\
\hline & Peak voltage $(\mathrm{V})$ & $-518 \sim-988$ \\
\hline & Peak current (A) & 254 194 \\
\hline & Pulse frequency $(\mathrm{Hz})$ & 332 \\
\hline & Pulse width $(\mu \mathrm{s})$ & 60 (duty cycle $2 \%$ ) \\
\hline \multirow{2}{*}{ Cr ion bombardment } & Synchronized bias voltage & -1000 V (pulse width $105 \mu \mathrm{s})$ \\
\hline & Bombardment time & $40 \mathrm{~s}$ \\
\hline \multirow{2}{*}{$\mathrm{Cr}-\mathrm{C}$ film deposition } & Synchronized bias voltage & -150 V (pulse width $105 \mu$ s) \\
\hline & Deposition time & $90 \mathrm{~min}$ \\
\hline Depositio & nperature $\left({ }^{\circ} \mathrm{C}\right)$ & 200 \\
\hline
\end{tabular}

Notes: high-power impulse magnetron sputtering (HiPIMS).

\section{Results and Discussion}

\subsection{Composition and Crystallographic Orientation}

The chromium contents in $\mathrm{Cr}-\mathrm{C}$ films deposited at different $\mathrm{C}_{2} \mathrm{H}_{2}$ gas flow ratio are shown in Figure 1. Some results of the higher $\mathrm{C}_{2} \mathrm{H}_{2}$ gas flow ratio were collected from the previous work [31]. The $\mathrm{Cr}$ concentration in films decreases near linearly with the increasing the $\mathrm{C}_{2} \mathrm{H}_{2}$ gas flow ratio. However, there is slope transition occurred around $\mathrm{Ar} / \mathrm{C}_{2} \mathrm{H}_{2}$ gas flow ratio 10:1. This is a common phenomenon of reactive dcMS with a metallic target $[33,39,40]$. As for low $\mathrm{C}_{2} \mathrm{H}_{2}$ gas flow rate, the reactive gas is not sufficient for all sputtered metal species. The target voltage shows no obvious change. The deposition is under the so-called metallic mode. However, when the $\mathrm{C}_{2} \mathrm{H}_{2}$ gas flow ratio reaches the critical value, the target voltage dramatically drops due to the target poisoning. Under this condition, the deposition transfers to the compound mode. Meanwhile, the release of sputtered metal species is reduced and the reactive gas becomes excessive. The composition of films deposited under the compound mode changes slightly with the reactive gas. This explains why most films obtained in our previous work presents a hydrogenated amorphous carbon main phase [31] and the pulse voltage varies greatly in this study (Table 1). However, these results seem against the impression that HiPIMS exhibits milder target poisoning due to the rarefaction of the reactive gas $[33,41]$. The mechanism is still unclear due to the complex interactions of each different metal, reactive gas, total pressure and pulse width [33].

The X-ray diffractograms of $\mathrm{Cr}-\mathrm{C}$ films deposited at different $\mathrm{C}_{2} \mathrm{H}_{2}$ flow rate fractions are shown in Figure 2. All films of the Ar $/ \mathrm{C}_{2} \mathrm{H}_{2}$ flow ratio from 10:1 and 38:1 with a Cr concentration from 16 at.\% to 75 at.\% exhibits a mainly X-ray amorphous structure. This result coincides with the series of studies which show that $\mathrm{Cr}-\mathrm{C}$ films with an $\mathrm{X}$-ray amorphous structure could be sputtering deposited in the entire composition range of $25-85$ at. $\%$ C at $300{ }^{\circ} \mathrm{C}[10,12,24,25]$. The amorphous $\mathrm{Cr}-\mathrm{C}$ film may include two separate phases, amorphous chromium-rich carbide and amorphous carbon phases. It seems there are more weak and broad peaks of chromium and carbide phases shown in those $\mathrm{Cr}-\mathrm{C}$ films with a relatively higher $\mathrm{Cr}$ concentration. 


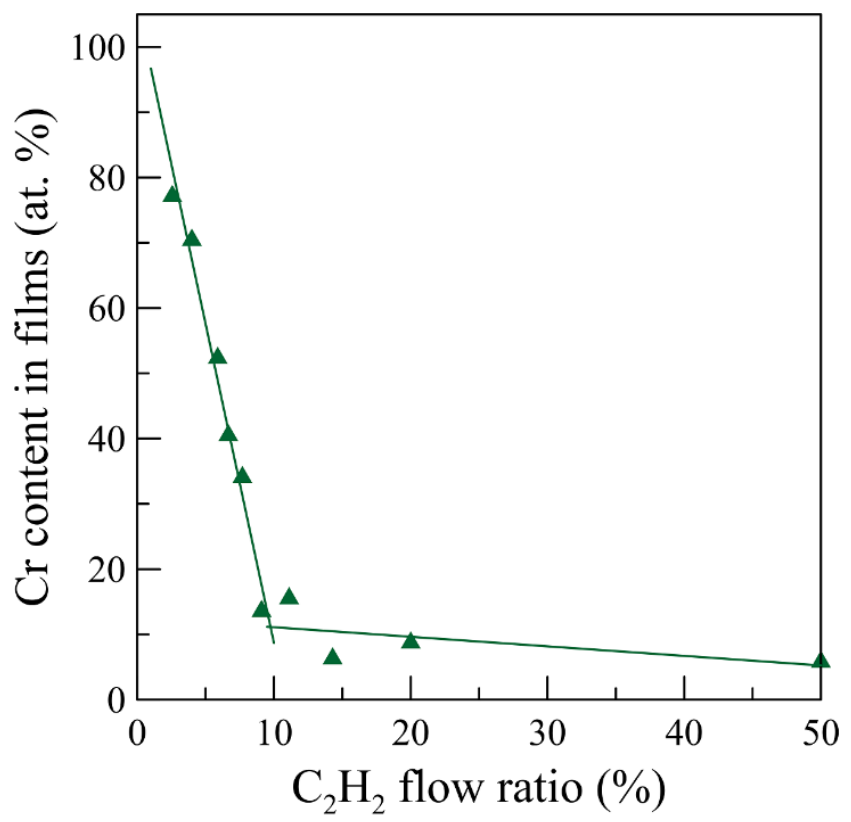

Figure 1. $\mathrm{Cr}$ atomic concentration in deposited $\mathrm{Cr}-\mathrm{C}$ film as a function of $\mathrm{C}_{2} \mathrm{H}_{2}$ gas fraction in $0.8 \mathrm{~Pa}$ deposition atmosphere.

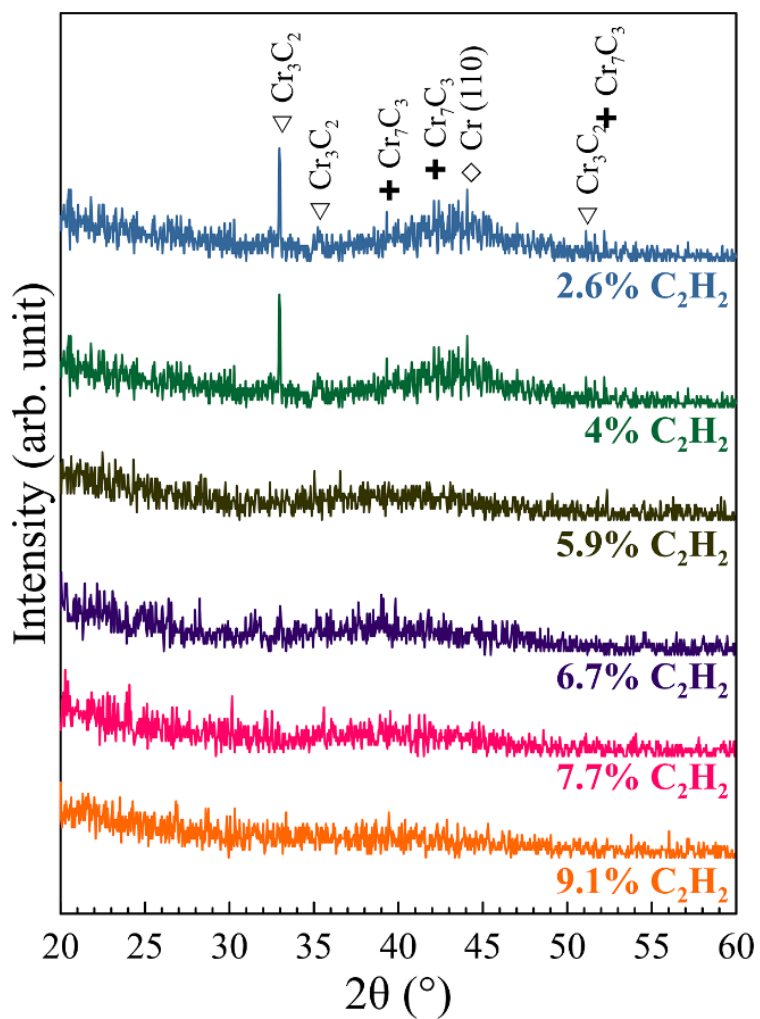

Figure 2. X-ray diffractograms of $\mathrm{Cr}-\mathrm{C}$ films deposited on $\mathrm{Si}$ (100) at $0.8 \mathrm{~Pa}$ deposition atmosphere with different $\mathrm{C}_{2} \mathrm{H}_{2}$ fractions with applying a substrate bias of $-150 \mathrm{~V}$.

In Figure 2, a broad feature become visible at about $36^{\circ} \sim 51^{\circ} 2 \theta$ when the chromium content reaches 27 at. $\%\left(7.7 \% \mathrm{C}_{2} \mathrm{H}_{2}\right.$ gas flow rate). The intensity of this broad feature increases with the decrease of $\mathrm{C}_{2} \mathrm{H}_{2}$ gas fraction and shifts from $39^{\circ}$ to higher angle $44^{\circ}$ when the carbon content reduced. This trend is consistent with the results in ref. [10]. Two possible factors that attributed this shift: the decreases of nanocrystalline high carbon phases, a-CrC and a-C:H and the increases of nanocrystalline high chromium phases, 
$\mathrm{Cr}_{7} \mathrm{C}_{3}, \mathrm{Cr}_{3} \mathrm{C}_{2}$ and $\mathrm{Cr}$. The decrease of $\mathrm{C}_{2} \mathrm{H}_{2}$ flow rate causes the decrease of carbon content in films and results the presence of nanocrystalline high chromium phases. Although HiPIMS usually produces a higher ionization ratio and a $-150 \mathrm{~V}$ substrate bias was applied to enhance the kinetic energy of the incident ions, the crystallinity of the deposited $\mathrm{Cr}-\mathrm{C}$ films is still similar to those dcMS sputtering deposited amorphous $\mathrm{Cr}-\mathrm{C}$ films. Similar cases could also be found in the comparison of $\mathrm{Cr}-\mathrm{C}$ films deposited by reactive dcMS and HiPIMS [12]. Crystalline phases appeared when the dcMS sputtering deposition temperature was raised to $500{ }^{\circ} \mathrm{C}$ [24]. Furthermore, crystalline phases also can only be found in $\mathrm{Cr}-\mathrm{C}$ films deposited by using cathodic arc deposition, which possess a fully ionized metal species, at over $-350 \mathrm{~V}$ substrate bias [7]. Therefore, the substrate bias voltage applied in this study might not be sufficient to induce a crystalline structure.

\subsection{Chemical Bonding}

The Raman spectra of the $\mathrm{Cr}-\mathrm{C}$ films deposited at different $\mathrm{C}_{2} \mathrm{H}_{2}$ flow ratio are shown in Figure 3. Only peaks of $\mathrm{G}\left(\sim 1580 \mathrm{~cm}^{-1}\right)$ and $\mathrm{D}\left(\sim 1350 \mathrm{~cm}^{-1}\right)$ bands of carbon phases can be identified in $\mathrm{Cr}-\mathrm{C}$ films deposited with a relatively higher $\mathrm{C}_{2} \mathrm{H}_{2}$ gas flow rate. These two peaks prove the presence of carbon phases in films with relatively higher carbon content. Intensities of both $\mathrm{D}$ and $\mathrm{G}$ bands decrease with the fraction of $\mathrm{C}_{2} \mathrm{H}_{2}$. That indicates the carbon phase reduce with the decrease of the carbon content in $\mathrm{Cr}-\mathrm{C}$ films. Similar trend also can be found for Ti-C films deposited by using same HiPIMS power [42]. The intensity of $\mathrm{D}$ band decreases more obviously. This indicates the decrease of number and clustering of rings [43].

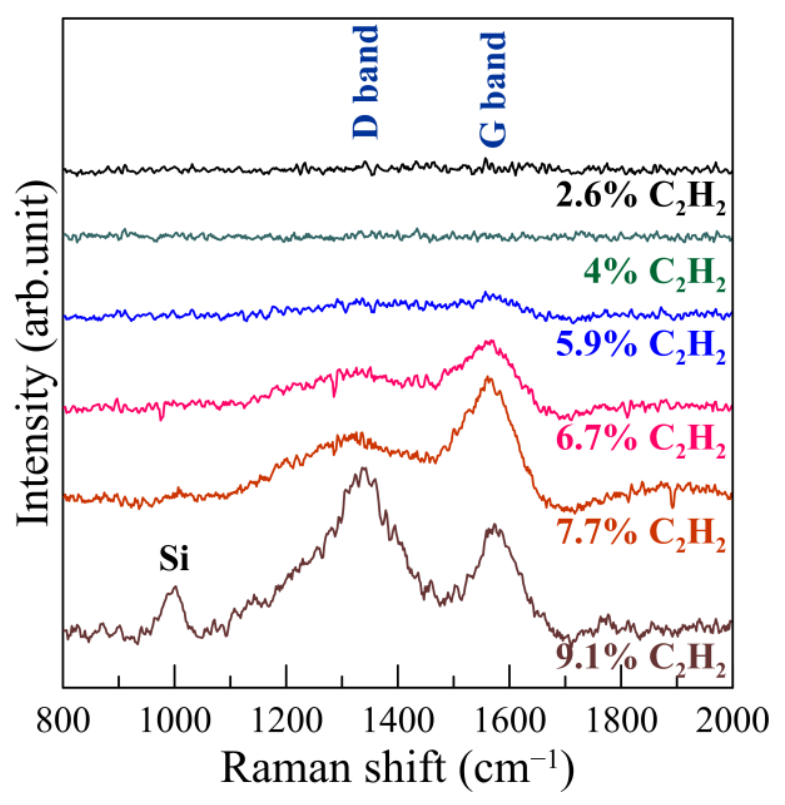

Figure 3. Raman spectra of $\mathrm{Cr}-\mathrm{C}$ films deposited on the $\mathrm{Si}(100)$ substrate with a substrate bias of $-150 \mathrm{~V}$ at $0.8 \mathrm{~Pa}$ deposition atmosphere with different $\mathrm{C}_{2} \mathrm{H}_{2}$ fractions.

The ESCA (XPS) C1s and Cr2p spectra of $\mathrm{Cr}-\mathrm{C}$ films deposited with different $\mathrm{C}_{2} \mathrm{H}_{2}$ gas flow ratios are shown in Figure 4. Due to the complex nature of the $\mathrm{C} 1 \mathrm{~s}$ spectra and the resolution limits of the equipment, the quantity of each component of different carbon cannot be estimated. Refer to ref. [24], the C1s is contributed by $\mathrm{C}-\mathrm{C}$ bonds and $\mathrm{C}-\mathrm{Cr}$ bonds. The $\mathrm{C}-\mathrm{C}$ bonds includes $\mathrm{sp}^{2}$ and $\mathrm{sp}^{3}$ bonding and the $\mathrm{C}-\mathrm{Cr}$ bonds might be contributed by $\mathrm{C}-\mathrm{Cr}(1)$ and $\mathrm{C}-\mathrm{Cr}$ (2) bonding, which correspond to $\mathrm{Cr}_{7} \mathrm{C}_{3}$ and $\mathrm{Cr}_{3} \mathrm{C}_{2}$ phase, respectively. It is obvious that main phase in high carbon films is the $\mathrm{sp}^{2}$ phase which decreases with reducing the carbon content in films. The carbide phases increase with reducing the $\mathrm{C}_{2} \mathrm{H}_{2}$ gas fraction and reaches to a maximum when the $\mathrm{Cr}$ concentration is over 52 at. $\%\left(5.9 \% \mathrm{C}_{2} \mathrm{H}_{2}\right.$ gas fraction), then decreases. This trend is consistent with the 
decrease of $\mathrm{D}$ and $\mathrm{G}$ bands in Raman spectra shown in Figure 3. The $\mathrm{sp}^{3}-\mathrm{C}$ phase decreases slightly with reducing the carbon content in films. These trends are similar to the results of Cr-C films deposited by non-reactive dcMS sputtering $[10,24,30]$. Similar results also can be found for Ti-C films deposited by using same HiPIMS power [42]. The bonding energy of $\mathrm{sp}^{2}-\mathrm{C}$ is relatively lower than that of $\mathrm{sp}^{3}-\mathrm{C}$. This would favor the carbon atoms of $\mathrm{sp}^{2}-\mathrm{C}$ to combine with the chromium atoms to form the carbide phases [44]. This explains the significant decrease of $\mathrm{sp}^{2}-\mathrm{C}$ and the increase of carbide phases with reducing the carbon content in films. The increase of $\mathrm{Cr} 2 \mathrm{p}$ intensity with the decrease of $\mathrm{C}_{2} \mathrm{H}_{2}$ gas fraction is consistent with the sharp slope in Figure 1. The bonding energies of two peaks also shift to higher value with the decrease of $\mathrm{C}_{2} \mathrm{H}_{2}$ gas fraction.
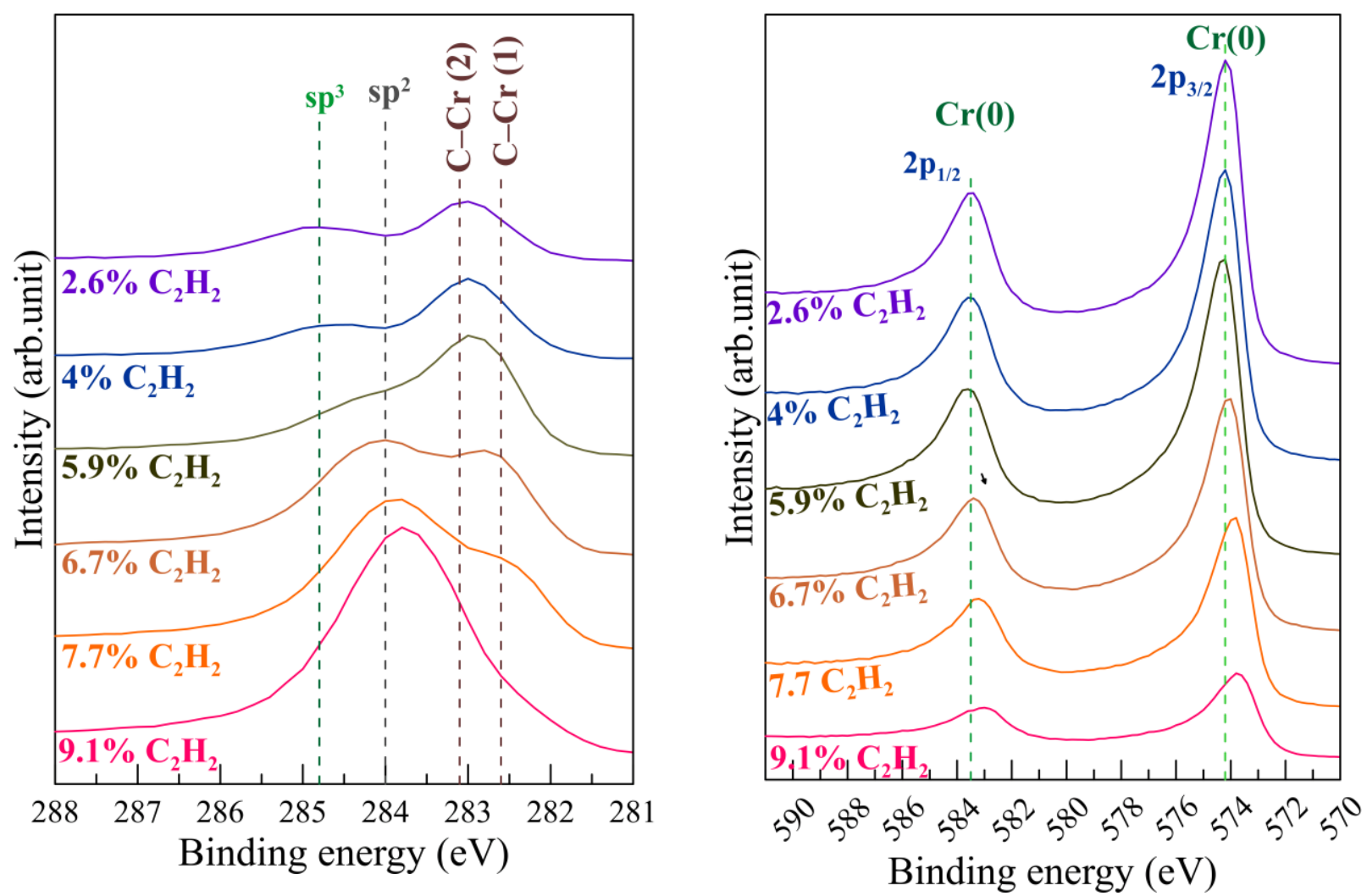

Figure 4. The ESCA (XPS) C1s (left) and Cr2p (right) spectra of Cr-C films deposited on the Si (100) substrate with a substrate bias of $-150 \mathrm{~V}$ at $0.8 \mathrm{~Pa}$ deposition atmosphere with different $\mathrm{C}_{2} \mathrm{H}_{2}$ gas fractions.

\subsection{Microstructure and Mechanical Properties}

The top and cross-sectional SEM SE micrographs of the $\mathrm{Cr}-\mathrm{C}$ films deposited at the pressure of $0.8 \mathrm{~Pa}$ with different $\mathrm{C}_{2} \mathrm{H}_{2}$ gas fraction are shown in Figure 5. The film of $9.1 \% \mathrm{C}_{2} \mathrm{H}_{2}$ gas fraction ( $\mathrm{Cr} 16$ at.\%) presents a loosen columnar structure with a feature of stacking clusters. This structure is similar to the reported reactive HiPIMS-deposited $[12,20]$ and non-reactive dcMS-deposited [10] $\mathrm{Cr}-\mathrm{C}$ films with a high carbon content. With the $\mathrm{C}_{2} \mathrm{H}_{2}$ gas fraction decrease, the film structure transfers to relatively denser columns with round cauliflower tops until 5.9\% $\mathrm{C}_{2} \mathrm{H}_{2}$ gas fraction ( $\mathrm{Cr} 52$ at.\%) is reached. Meanwhile, no obvious granular edge was found between the columns. These are also similar to those medium chromium content films reported in ref. $[10,12,20]$. As for the films of $4 \% \mathrm{C}_{2} \mathrm{H}_{2}$ gas fraction ( $\mathrm{Cr} 66.6$ at.\%) and $2.6 \% \mathrm{C}_{2} \mathrm{H}_{2}$ gas fraction $(\mathrm{Cr} 75$ at.\%), the film morphologies change drastically. No columnar feature can be found on the top and on the cross-sectional of these two films. The top of two films is flat with a feature of segregation phase surrounding the boundary of the matrix domains. The segregation phase in the boundary could be amorphous carbon and the surrounded matrix could be amorphous 
carbide phase [25]. The cross-section of two films is also as flat as the cleaved glass. All these features are commonly seen in amorphous films deposited at low temperature or a high cooling rate. These features support the results of $\mathrm{X}$-ray diffraction. There are intergranular cracks on the film of $2.6 \% \mathrm{C}_{2} \mathrm{H}_{2}$ gas fraction $(\mathrm{Cr} 75$ at. $\%$ ), which might be induced by the huge internal stress and the difference of the elastic moduli between the carbon and carbide phases.
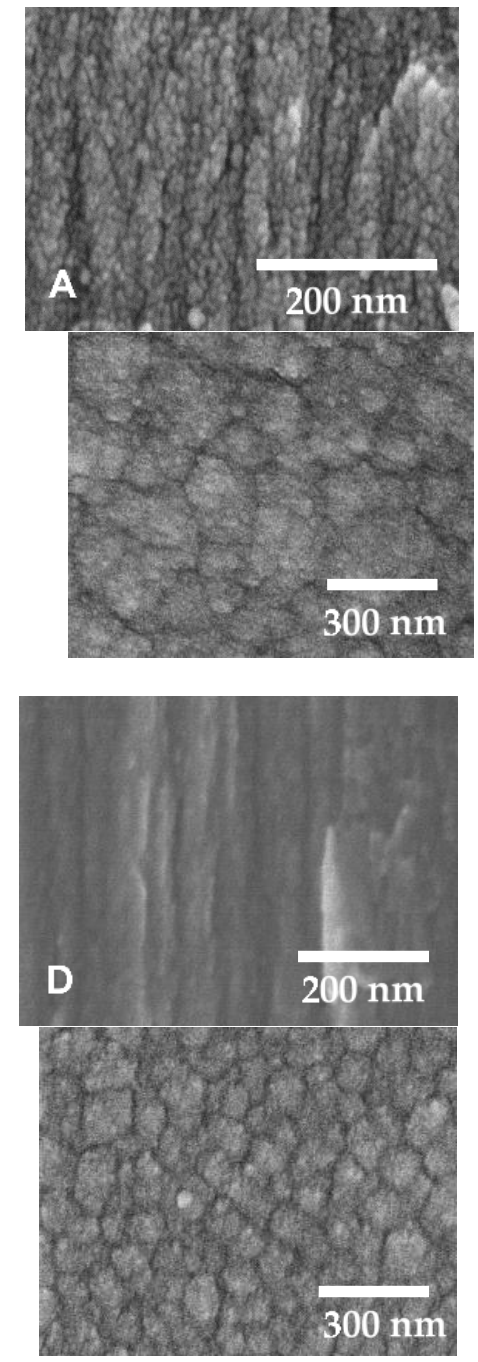
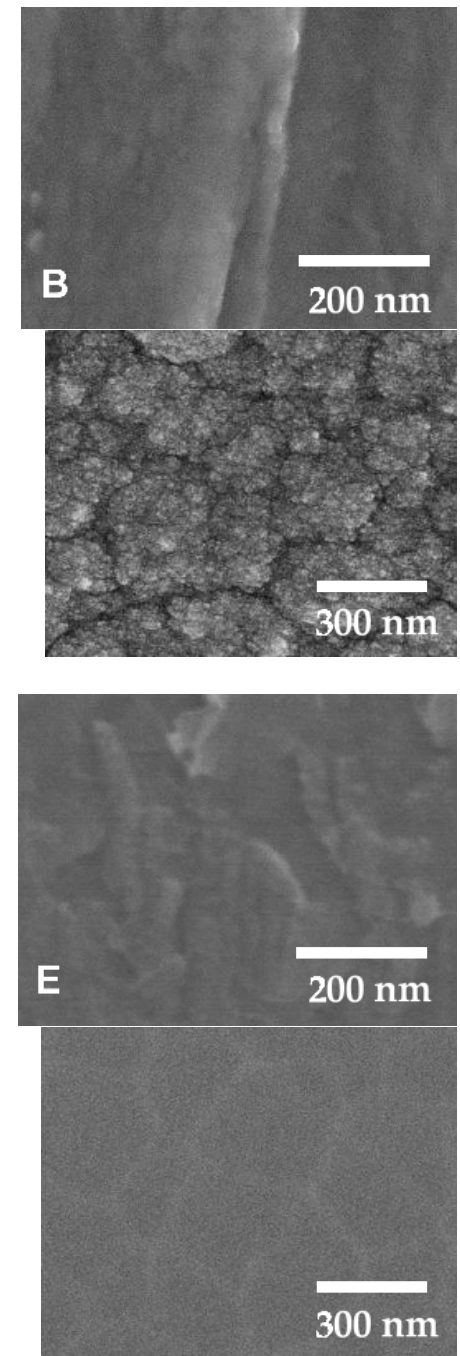
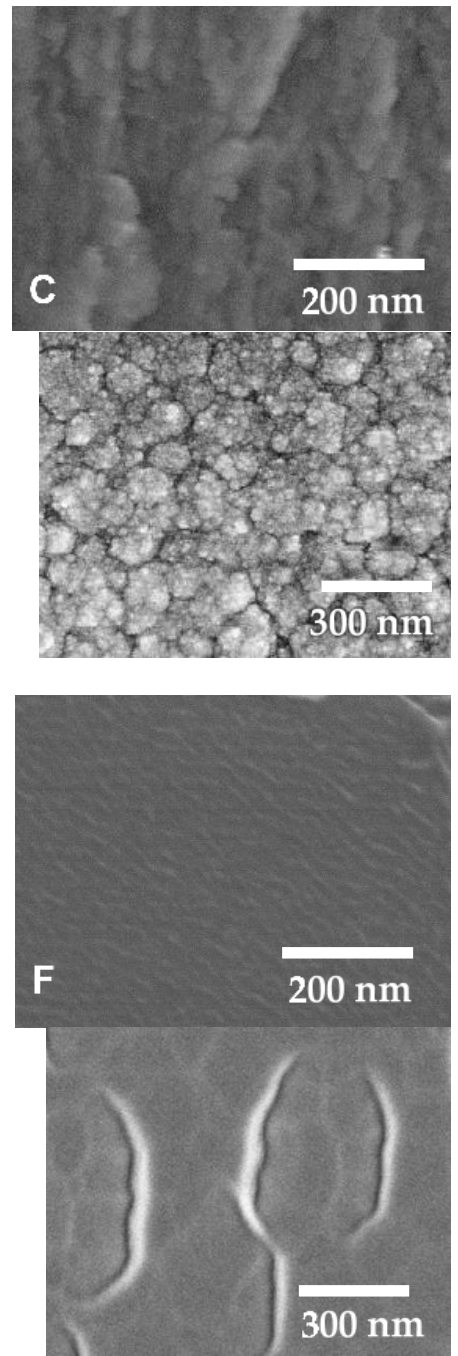

Figure 5. The top (up) and cross-sectional (down) SEM SE micrographs of Cr-C films deposited on Si (100) substrate at $0.8 \mathrm{~Pa}$ deposition atmosphere of $(\mathbf{A}) 9.1 \%$, (B) $7.7 \%$, (C) $6.7 \%$, (D) $5.9 \%$, (E) $4 \%$ and (F) $2.6 \% \mathrm{C}_{2} \mathrm{H}_{2}$ gas fraction with a substrate bias of $-150 \mathrm{~V}$.

As mentioned in Introduction, the amorphous carbon phases usually exhibit a high hardness/elastic modulus ratio and the carbide phases usually exhibit both high hardness and high elastic modulus. The fraction changes of the carbon and carbide phases in $\mathrm{Cr}-\mathrm{C}$ film can significantly affect the mechanical properties of films [12,13,15].

The average hardness and the elastic modulus of $\mathrm{Cr}-\mathrm{C}$ films deposited at different $\mathrm{C}_{2} \mathrm{H}_{2}$ gas fractions measured by the nanoindentation are shown in Figure 6 . Both the harness and elastic modulus increases with the decrease of the $\mathrm{C}_{2} \mathrm{H}_{2}$ gas fraction and the carbon content. The trend and values are very similar to the $\mathrm{Cr}-\mathrm{C}$ films deposited by using the reactive dcMS under the $\mathrm{Ar} / \mathrm{CH}_{4}$ mixture atmosphere [15]. In ref. [10], it was concluded that both the film hardness and the film elasticity increase with the fraction of $\mathrm{C}-\mathrm{Cr}$ bonds in film deposited by using dcMS. In the ref. [12], it was found that both the 
film hardness and the film elasticity decrease with the fraction of a-C:H phase in films deposited by dcMS and HiPIMS. These similar relationships of mechanical properties on the fraction of the carbon and carbide phases are consistent with the chemical analysis results in the previous section. The large measurement deviations could be attributed to the microscale non-uniform coexistence of the multiple phases, including a-CrC, a-C:H, nanocrystalline carbide, chromium and droplets, in the film structure [31]. The loosen structure of the amorphous carbon films deposited under the excess $\mathrm{C}_{2} \mathrm{H}_{2}$ gas fraction and the compound mode target behavior show the lowest film hardness and the largest deviation value. Decreasing the $\mathrm{C}_{2} \mathrm{H}_{2}$ flow rate in the deposition atmosphere reduces the carbon content in the deposited films. This promotes the formation of carbide and consequently enhances the film hardness and elasticity. However, the hardness/elastic modulus (H/E) ratio, which is an indicator to better wear resistance [45], also decreases with the carbon phases. This results in the loss of adaptation of strain and may cause the intergranular cracks shown in Figure 5F.

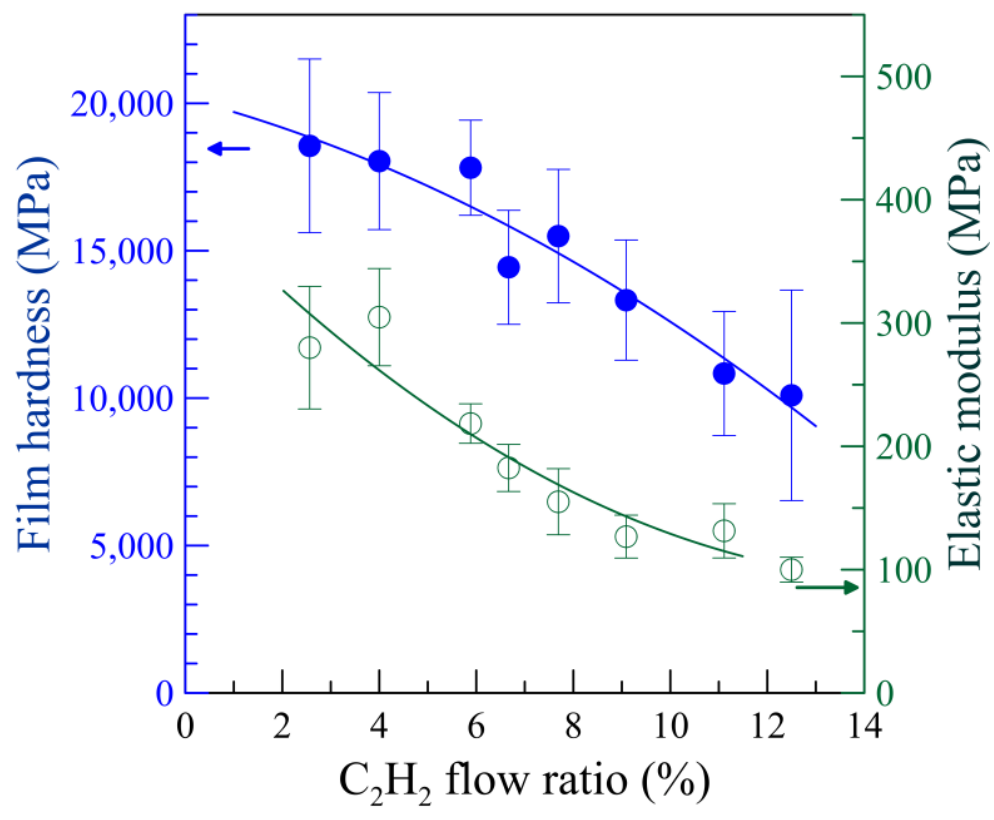

Figure 6. Mean values and standard deviations for nanoindentation hardness $(\mathrm{H})$ and elastic modulus (E) for Cr-C films deposited on the Si (100) substrate with a substrate bias of $-150 \mathrm{~V}$ at $0.8 \mathrm{~Pa}$ deposition atmosphere with different $\mathrm{C}_{2} \mathrm{H}_{2}$ gas fractions.

\section{Conclusions}

In this research, chromium-carbon films were deposited by utilizing reactive highpower impulse magnetron sputtering under the same condition of deposition temperature, pulse frequency, duty cycle, average power of the chromium cathode, but with different mixture ratios of ethyne and argon with a constant deposition total pressure of $0.8 \mathrm{~Pa}$. After investigating the microstructure, composition and chemical bonding of the obtained films, several conclusions are made. In the range of the $\mathrm{C}_{2} \mathrm{H}_{2}$ gas fraction used in this work, all obtained $\mathrm{Cr}-\mathrm{C}$ films are $\mathrm{X}$-ray amorphous. With the $\mathrm{C}_{2} \mathrm{H}_{2}$ gas ratio decrease, the chromium concentration in films increases linearly with two slopes, which can be attributed to the metallic mode deposition and compound mode deposition respectively. With the chromium concentration increase, the microstructure of the obtained film changes from a loosen staking-clusters structure into a columnar structure, and then a dense glassy structure. Moreover, the $\mathrm{sp}^{2}-\mathrm{C}$ bonding decreases, but the $\mathrm{Cr}-\mathrm{C}$ bonding increases with the carbon content decrease. This proves that the main phase of the films changes from a hydrogenated amorphous carbon phase into the glassy amorphous chromium carbide. These changes of the microstructure and phases cause a large difference in the film hardness. 
The increase of amorphous carbide phases results in the higher hardness and the higher elastic modulus.

Author Contributions: Conceptualization, C.-C.K.; data curation, S.-P.C.; funding acquisition, C.C.K.; investigation, C.-C.K.; methodology, C.-C.K.; project administration, C.-C.K.; resources, C.C.K.; writing-original draft, C.-C.K. All authors have read and agreed to the published version of the manuscript.

Funding: This research received no external funding.

Institutional Review Board Statement: Not applicable.

Informed Consent Statement: Not applicable.

Data Availability Statement: Not applicable.

Acknowledgments: The authors wish to thank Supati Cooperation for financial support. Precision Instrument Support Center of Feng Chia University and The Central Regional Instrument Center of National Chung Hsing University are also acknowledged for the microstructure analysis instruments.

Conflicts of Interest: The authors declare no conflict of interest.

\section{References}

1. Pierson, H.O. Handbook of Refractory Carbides and Nitrides, 1st ed.; Noyes Publications: Park Ridge, NJ, USA, $1996 ;$ pp. $100-116$.

2. Oyama, S.T. The Chemistry of Transition Metal Carbides and Nitrides; Springer: Dordrecht, The Netherlands, 1996; pp. 28-52. [CrossRef]

3. Nedfors, N.; Tengstrand, O.; Lewin, E.; Furlan, A.; Eklund, P.; Hultman, L.; Jansson, U. Structural, mechanical and electricalcontact properties of nanocrystalline-NbC/amorphous-C coatings deposited by magnetron sputtering. Surf. Coat. Technol. 2011, 206, 354-359. [CrossRef]

4. Lewin, E.; Wilhelmsson, O.; Jansson, U. Nanocomposite nc-TiC/a-C thin films for electrical contact applications. J. Appl. Phys. 2006, 100, 054303. [CrossRef]

5. Aubert, A.; Gillet, R.; Gaucher, A.; Terrat, J.P. Hard chrome coatings deposited by physical vapour deposition. Thin Solid Films 1983, 108, 165-172. [CrossRef]

6. Merl, D.K.; Panjan, P.; Čekada, M.; Maček, M. The corrosion behavior of Cr-(C,N) PVD hard coatings deposited on various substrates. Electrochim. Acta. 2004, 49, 1527-1533. [CrossRef]

7. Lin, C.C.; Lee, J.W.; Chang, K.L.; Hsieh, W.J.; Wang, C.Y.; Chang, Y.A.; Shih, H.C. The effect of the substrate bias voltage on the mechanical and corrosion properties of chromium carbide thin films by filtered cathodic vacuum arc deposition. Surf. Coat. Technol. 2006, 200, 2679-2685. [CrossRef]

8. Edigaryan, A.A.; Safonov, V.A.; Lubnin, E.N.; Vykhodtseva, L.N.; Chusova, G.E.; Polukarov, Y.M. Properties and preparation of amorphous chromium carbide electroplates. Electrochim. Acta. 2002, 47, 2775-2786. [CrossRef]

9. Esteve, J.; Romero, J.; Gómez, M.; Lousa, A. Cathodic chromium carbide coatings for molding die applications. Surf. Coat. Technol. 2004, 188-189, 506-510. [CrossRef]

10. Andersson, M.; Högström, J.; Urbonaite, S.; Furlan, A.; Nyholm LJansson, U. Deposition and characterization of magnetron sputtered amorphous Cr-C films. Vacuum 2012, 86, 1408-1416. [CrossRef]

11. Maréchal, N.; Quesnel, E.; Pauleau, Y. Deposition process and characterization of chromium-carbon coatings produced by direct sputtering of a magnetron chromium carbide target. J. Mater. Res. 1994, 9, 1820-1828. [CrossRef]

12. Nygren, K.; Samuelsson, M.; Flink, A.; Ljungcrantz, H.; Rudolphi, Å.K.; Jansson, U. Growth and characterization of chromium carbide films deposited by high rate reactive magnetron sputtering for electrical contact applications. Surf. Coat. Technol. 2014, 260, 326-334. [CrossRef]

13. Dai, W.; Wu, G.; Wang, A. Structure and elastic recovery of $\mathrm{Cr}-\mathrm{C}: \mathrm{H}$ films deposited by a reactive magnetron sputtering technique. Appl. Surf. Sci. 2010, 257, 244-248. [CrossRef]

14. Ziebert, C.; Ye, J.; Stüber, M.; Ulrich, S.; Edinger, M.; Barzen, I. Ion bombardment-induced nanocrystallization of magnetronsputtered chromium carbide thin films. Surf. Coat. Technol. 2011, 205, 4844-4849. [CrossRef]

15. Gassner, G.; Mayrhofer, P.H.; Mitterer, C.; Kiefer, J. Structure-property relations in Cr-C/a-C:H coatings deposited by reactive magnetron sputtering. Surf. Coat. Technol. 2005, 200, 1147-1150. [CrossRef]

16. Poletika, I.M.; Ivanov, S.F.; Gnyusov SF\& Perovskaya, M.V. Electron-beam deposition of chromium carbide-based coatings with an ultradispersed structure or a nanostructure. Russ. Metall. 2016, 1275-1282. [CrossRef]

17. Wolfe, D.E.; Singh, J.; Narasimhan, K. Synthesis of titanium carbide/chromium carbide multilayers by the co-evaporation of multiple ingots by electron beam physical vapor deposition. Surf. Coat. Technol. 2002, 160, 206-218. [CrossRef]

18. Li, Z.-L.; Chen, Y.-Y.; Wang, C.-J.; Lee, J.-W. Comparison of chromium carbide thin films grown by different power supply systems. Surf. Coat. Technol. 2018, 353, 329-338. [CrossRef] 
19. Konishi, T.; Yukimura, K.; Takaki, K. Fabrication of diamond-like carbon films using short-pulse HiPIMS. Surf. Coat. Technol. 2016, 286, 239-245. [CrossRef]

20. Tillmann, W.; Dias, N.F.L.; Stangier, D. Tribo-mechanical properties of CrC/a-C thin films sequentially deposited by HiPIMS and mfMS. Surf. Coat. Technol. 2018, 335, 173-180. [CrossRef]

21. Richert, M.; Mazurkiewicz, A.; Smolik, J. Chromium carbide coatings obtained by the hybrid PVD methods. J. Achiev. Mater. Manuf. Eng. 2010, 43, 145-152.

22. Jiang, C. First-principles study of structural, elastic, and electronic properties of chromium carbides. Appl. Phys. Lett. 2008, 92, 041909. [CrossRef]

23. Bauer-Grosse, E. Thermal stability and crystallization studies of amorphous TM-C films. Thin Solid Films 2004, 447-448, 311-315 [CrossRef]

24. Nygren, K.; Andersson, M.; Högström, J.; Fredriksson, W.; Edström, K.; Nyholm, L.; Jansson, U. Influence of deposition temperature and amorphous carbon on microstructure and oxidation resistance of magnetron sputtered nanocomposite $\mathrm{CrC}$ films. Appl. Surf. Sci. 2014, 305, 143-153. [CrossRef]

25. Jansson, U.; Lewin, E. Sputter deposition of transition-metal carbide films-A critical review from a chemical perspective. Thin Solid Films 2013, 536, 1-24. [CrossRef]

26. Cheng, Y.Q.; Ma, E. Atomic-level structure and structure-property relationship in metallic glasses. Prog. Mat. Sci. 2011, 56, 379-473. [CrossRef]

27. Bauer-Grosse, E.; Aouni, A. Glass-forming range and glass thermal stability in binary 3d TM-C systems. J. Non-Cryst. Solids 2007, 353, 3644-3649. [CrossRef]

28. Music, D.; Kreissig, U.; Mertens, R.; Schneider, J.M. Electronic structure and mechanical properties of $\mathrm{Cr}_{7} \mathrm{C}_{3}$. Phys. Lett. A 2004, 326, 473-476. [CrossRef]

29. Magnuson, M.; Andersson, M.; Lu, J.; Hultman, L.; Jansson, U. Electronic structure and chemical bonding of amorphous chromium carbide thin films. J. Phys. Condens. Matter 2012, 24, 225004. [CrossRef]

30. Groudeva-Zotova, S.; Vitchev, R.G.; Blanpain, B. Phase composition of $\mathrm{Cr}-\mathrm{C}$ thin films deposited by a double magnetron sputtering system. Surf. Interface Anal. 2000, 30, 544-548. [CrossRef]

31. Kuo, C.C.; Lin, C.H.; Chang, J.T.; Lin, Y.T. Reactive High Power Impulse Magnetron Sputtering of Chromium-Carbon Films. Coatings 2020, 10, 1269. [CrossRef]

32. Lundin, D.; Minea, T.; Gudmundsson, J.T. High Power Impulse Magnetron Sputtering: Fundamentals, Technologies, Challenges and Applications; Elsevier: Amsterdam, The Netherlands, 2019. [CrossRef]

33. Anders, A. Tutorial: Reactive high power impulse magnetron sputtering (R-HiPIMS). J. Appl. Phys. 2017, 121, 171101. [CrossRef]

34. Kouznetsov, V.; Macak, K.; Schneider, J.; Helmersson, U.; Petrov, I. Hybrid HIPIMS and DC magnetron sputtering deposition of TiN coatings: Deposition rate, structure and tribological properties. Surf. Coat. Technol. 1999, 12, 290. [CrossRef]

35. Machunze, R.; Ehiasarian, A.; Tichelaar, F.; Janssen, G.; Ehiasarian, A. Stress and texture in HIPIMS TiN thin films. Thin Solid Films 2009, 518, 1561-1565. [CrossRef]

36. Kuo, C.C.; Lin, C.H.; Lin, Y.T.; Chang, J.T. Effects of cathode voltage pulse width in high power impulse magnetron sputtering on the deposited chromium thin films. Coatings 2020, 10, 542. [CrossRef]

37. Kuo, C.C.; Lin, C.H.; Chang, J.T.; Lin, Y.T. Effect of voltage pulse width and synchronized substrate bias in high power impulse magnetron sputtering of zirconium films. Coatings 2021, 11, 7. [CrossRef]

38. Greczynski, G.; Lu, J.; Jensen, J.; Bolz, S.; Kölker, W.; Schiffers, C.; Lemmer, O.; Greene, J.E.; Hultman, L. A review of metal-ionflux-controlled growth of metastable TiAlN by HIPIMS/DCMS co-sputtering. Surf. Coat. Technol. 2014, 257, 15-25. [CrossRef]

39. Carneiro, J.O.; Machado, F.; Rebouta, L.; Vasilevskiy, M.I.; Lanceros-Méndez, S.; Teixeira, V.; Costa, M.F.; Samantilleke, A.P. Compositional, optical and electrical characteristics of $\mathrm{SiO}_{\mathrm{x}}$ thin films deposited by reactive pulsed DC magnetron sputtering. Coatings 2019, 9, 468. [CrossRef]

40. Saringer, C.; Franz, R. Effect of discharge power on target poisoning and coating properties in reactive magnetron sputter deposition of TiN. J. Vac. Sci. Technol. A 2016, 34, 041517. [CrossRef]

41. Horwat, D.; Anders, A. Compression and strong rarefaction in high power impulse magnetron sputtering discharges. J. Appl. Phys. 2010, 108, 123306. [CrossRef]

42. Jiang, X.; Yang, F.-C.; Lee, J.-W.; Chang, C.-L. Effect of an optical emission spectrometer feedback-controlled method on the characterizations of nc-TiC/a-C:H coated by high power impulse magnetron sputtering. Diam. Relat. Mater. 2017, 73, 19-24. [CrossRef]

43. Ferrari, A.C.; Robertson, J. Interpretation of Raman spectra of disordered and amorphous carbon. Phys. Rev. B 2000, 61, 14095-14107. [CrossRef]

44. Dai, W.; Ke, P.; Wang, A. Microstructure and property evolution of Cr-DLC films with different Cr content deposited by a hybrid beam technique. Vacuum 2011, 85, 792-797. [CrossRef]

45. Leyland, A.; Matthews, A. Design criteria for wear-resistant nanostructured and glassy-metal coatings. Surf. Coat. Technol. 2004, 177-178, 317-324. [CrossRef] 